\title{
AN EXTENSION OF A GEOMETRIC INEQUALITY OF FINITE POINT SET ON A SPHERE IN THE CONSTANT CURVATURE SPACE
}

\author{
HANFANG ZHANG
}

Abstract. In this paper, we first prove an algebraic inequality, then use it obtain an extension of a geometirc inequality in the $n$-dimensional constant curvature space.

Mathematics subject classification (2000): 52A40, 51M05.

Key words and phrases: inequality, finite point set, circumradius.

\section{REFERENCES}

[1] Q. J. MaO, Two inequalities for finite set in $n$ dimensional spherical space, J. of Math. reserch \& exposition 174 (1997), 524-526.

[2] E. F. Beckenbach \& R. Bellman, Inequalities [M], Fourth Printing, Springer-Verlag (1983), 30-32.

[3] D. S. Mitrović, D. Analytic inequalities, Springer-Verlag (1970).

[4] S. G. YANG, Two results on Metric addition in spherical space, Northeast Math. J. 133 (1997), 375-360.

[5] L. YANG AND J. Z. ZHANG, Some metric problems in non-Euclidean hyperbolic geometry (I), isogonal imbedding and metric equation, J. China Univ. Mat. Sci. Technol (special issue or colum) 5 (1983), 123-134 (in Chinese).

[6] J. Z. ZHANG AND L. YANG, A class of geometric inequalities concening the mass-points system, J. China Univ. Sci. Technol 111 (1981), 1-8 (in Chinese). 